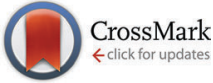

Cite this: Phys. Chem. Chem. Phys.,

Received 11th September 2015 Accepted 13th October 2015

DOI: $10.1039 / \mathrm{c} 5 \mathrm{cp} 05444 \mathrm{c}$

www.rsc.org/pccp $2015,17,30440$

\section{Interplay of experiment and theory: high resolution infrared spectrum and accurate equilibrium structure of $\mathrm{BF}_{2} \mathrm{OH} \dagger$}

\author{
Natalja Vogt, ${ }^{a b}$ Jean Demaison, ${ }^{a}$ Heinz Dieter Rudolph ${ }^{a}$ and Agnès Perrin ${ }^{c}$
}

\begin{abstract}
The high-resolution Fourier transform infrared (FTIR) spectrum of ${ }^{11} \mathrm{BF}_{2} \mathrm{OH}$ (difluoroboric acid) is analyzed taking into account numerous interactions. The $\nu_{1}, \nu_{2}$ and $\nu_{3}$ infrared bands are analyzed for the first time, whereas the parameters of the $6^{1}, 7^{1}, 8^{1}$ and $9^{1}$ states and for the $4^{1}$ and $9^{2}$ interacting states are redetermined. These results are used to check the quality of the ab initio force field. It is found that the ab initio rovibrational corrections are more accurate than the experimental ones. An earlier attempt to determine a semiexperimental structure did not allow us to obtain an accurate equilibrium structure. The reasons of this failure are investigated. This failure was mainly due to the lack of useful experimental information. Indeed, there is no isotopic substitution available for the fluorine atoms, and the boron atom is extremely close to the center of mass. Furthermore, the available isotopic substitutions $\left(H \rightarrow D\right.$ and $\left.{ }^{16} \mathrm{O} \rightarrow{ }^{18} \mathrm{O}\right)$ induce a large rotation of the principal axis system which amplifies the errors. However, the mixed estimation method has allowed us to determine a complete and reliable equilibrium structure. Thanks to this method, it is possible to determine an accurate structure, even in extremely difficult cases. An extensive analysis of the quality of structure calculations at the CCSD(T) level is also performed using basis sets up to five $\zeta$ quality. It was found that, at the convergence limit, the effects of the diffuse functions are practically disappearing, whereas the core-core and core-valence electron correlation effects are quite important for the bond lengths.
\end{abstract}

\section{Introduction}

The spectra and structure of difluorohydroxyborane molecule or difluoroboric acid, $\mathrm{BF}_{2} \mathrm{OH}$, were studied several times by experimental and theoretical methods. Nevertheless, there are still several problems that could not be solved until now. The molecule was first detected by mass spectrometry. ${ }^{1}$ The microwave spectrum of this planar asymmetric rotor was measured several times. ${ }^{2-5}$ The matrix infrared (IR) spectra of eight isotopologues were first observed by Jacox $e t a l .{ }^{6}$ Some of these data for the ${ }^{11} \mathrm{~B}$ isotopic species of $\mathrm{BF}_{2} \mathrm{OH}$ are also summarized in Table 1, which otherwise quotes the available high resolution infrared data. The first high resolution gas phase IR spectrum of $\mathrm{BF}_{2} \mathrm{OH}$ was observed by Collet et al. ${ }^{7}$ using a Fourier transform

\footnotetext{
${ }^{a}$ Section of Chemical Information Systems, University of Ulm, D-89069 Ulm, Germany.E-mail: natalja.vogt@uni-ulm.de

${ }^{b}$ Department of Chemistry, Lomonosov Moscow State University, 119991 Moscow, Russia

${ }^{c}$ Laboratoire Inter-Universitaire des Systèmes Atmosphériques (LISA), UMR 7583 CNRS et Universités Paris-Est Créteil et Paris Diderot-Paris 7, Institut Pierre-Simon Laplace, 61 Avenue du Général de Gaulle, 94010 Créteil Cedex, France

$\dagger$ Electronic supplementary information (ESI) available: Tables S1-S4. See DOI: $10.1039 / \mathrm{c} 5 \mathrm{cp} 05444 \mathrm{c}$
}

spectrometer, and this study led to the first investigation of the $\nu_{8}$ and $\nu_{9}$ fundamental bands of ${ }^{11} \mathrm{~B}$ (for the ${ }^{11} \mathrm{BF}_{2} \mathrm{OH}$ and ${ }^{10} \mathrm{BF}_{2} \mathrm{OH}$ isotopic species we will use henceforth in the text the abbreviated notation ${ }^{11} \mathrm{~B}$ and ${ }^{10} \mathrm{~B}$, respectively). Subsequently, the high-resolution infrared spectrum was recorded by Fourier transform spectroscopy in the range $400-4000 \mathrm{~cm}^{-1} .8$ At that time no significant resonances were observed during the investigation of the $v_{5}, v_{8}, \nu_{9}$ and $\nu_{8}+v_{9}$ bands. On the other hand the $\nu_{7}$ band was found to be affected by a C-type Coriolis resonance coupling together the $7^{1}$ energy levels with those from the dark $6^{1}$ state. Finally, the $v_{4}$ and $2 \nu_{9}$ bands, ${ }^{9}$ which correspond to the $\mathrm{OH}$ in-plane bending mode and to the first overtone of $\nu_{9}(\mathrm{OH}$ torsion relative to the $\mathrm{F}_{2} \mathrm{BO}$ moiety), respectively, are strongly perturbed. Indeed, the energy levels of the $9^{2}$ state are involved in B-type Coriolis resonances with those of the $6^{1} 9^{1}$ dark state. Moreover, the $4^{1}$ levels are perturbed by B-type Coriolis resonances with $7^{1} 9^{1}$ levels and by C-type Coriolis and anharmonic resonances with the $6^{1} 7^{1}$ levels. In addition to these rather "classical" perturbations, large amplitude effects were evidenced during the analysis of the $2 \nu_{9}$ and $\nu_{4}$ bands ${ }^{8}$ and of the $3 v_{9}-\nu_{9}$ hot band. ${ }^{10}$ To give an order of magnitude, for low $K_{a}$ values, tunnelling splittings of about $0.0051,0.0038$ and $0.031 \mathrm{~cm}^{-1}$ were observed for the energy levels of the $9^{2}, 4^{1}$ and $9^{3}$ states, respectively. There is a slow decrease of these splittings for high $K_{a}$ values that are difficult to observe in the 
Table 1 Fundamental bands of ${ }^{11} \mathrm{BF}_{2} \mathrm{OH}$ and interactions (values in $\mathrm{cm}^{-1}$ when pertinent)

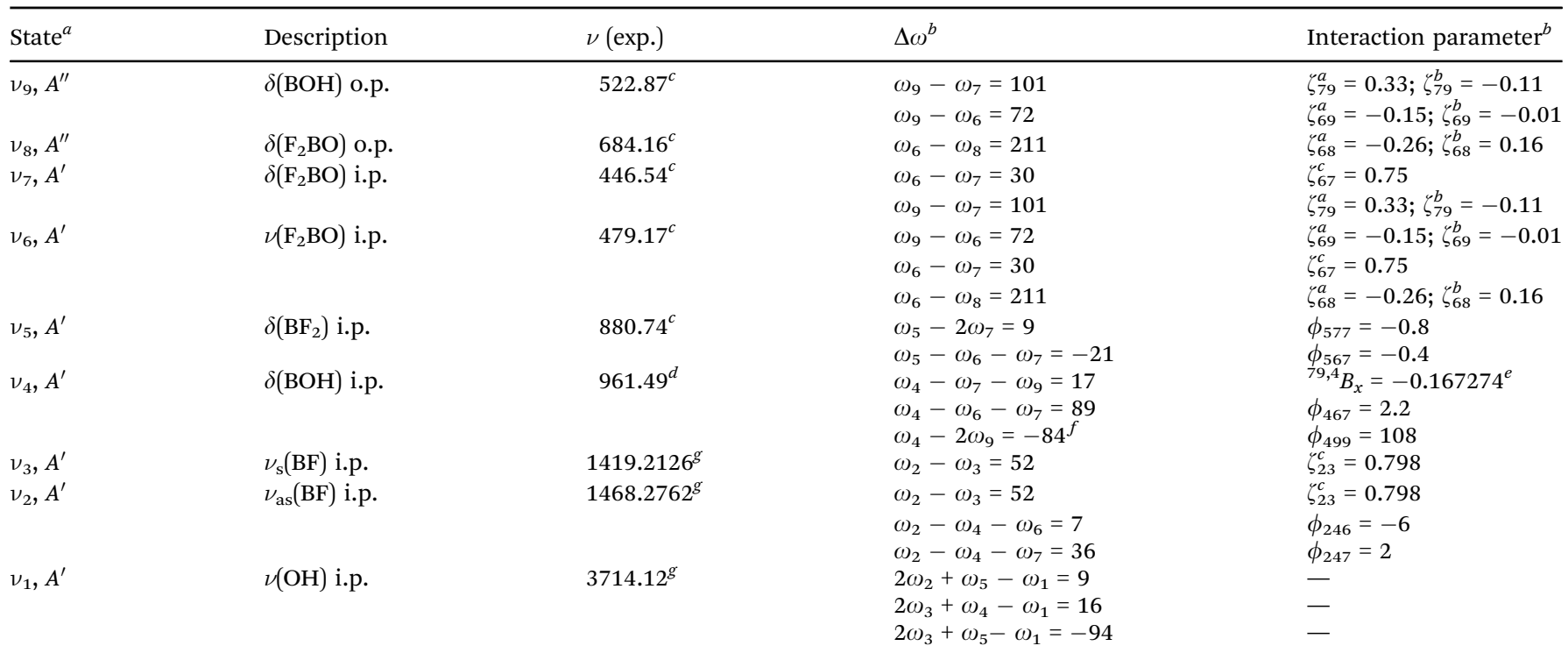

${ }^{a} A^{\prime}$ and $A^{\prime \prime}$ are the symmetry species in the $C_{\mathrm{s}}$ point group. ${ }^{b} \mathrm{CCSD}(\mathrm{T}) \_\mathrm{AE} / \mathrm{TZ} 2 \mathrm{Pf}$ value, see text; $\Delta \omega$ is the harmonic frequency. ${ }^{c}$ Gas phase band centers from ref. 8. ${ }^{d}$ Gas phase band centers from ref. 9. ${ }^{e}$ Experimental value, this work. ${ }^{f}$ Experimental value for $2 \nu_{9}=1042.87 \mathrm{~cm}^{-1} .{ }^{g} \mathrm{~g}^{\mathrm{T}}$ Th work.

infrared region. These large amplitude effects for $\mathrm{BF}_{2} \mathrm{OH}$ were confirmed by a careful reinvestigation of the rotational spectrum by millimeterwave spectroscopy. ${ }^{5}$ In this study, torsional splittings were found for most of the rotational transitions within the ground state and could be satisfactorily reproduced using the IAM (internal axis method) formalism. Using this approach, reasonable agreement between the ab initio (0.0061 and $0.0043 \mathrm{~cm}^{-1}$ ) and experimental $\left(0.0038\right.$ and $\left.0.0051 \mathrm{~cm}^{-1}\right)$ tunnelling splittings for the $4^{1}$ and $9^{2}$ states could be achieved. These results were later confirmed by another $a b$ initio study. ${ }^{11}$

$A b$ initio calculations predict the existence of many vibrationalrotational resonances perturbing the rotational structure of most vibrational states of $\mathrm{BF}_{2} \mathrm{OH}^{4}{ }^{4}$ These additional resonances which were not accounted for during our previous energy level calculations ${ }^{7-9}$ will be considered here for the $6^{1}, 7^{1}, 8^{1}$ and $9^{1}$ states and for the $4^{1}$ and $9^{2}$ interacting states.

The equilibrium geometry and anharmonic force field up to semidiagonal quartic terms have been calculated at the coupled cluster level of theory including a perturbational estimate of the effects of connected triple excitations $[\operatorname{CCSD}(\mathrm{T})] .^{4}$ The semiexperimental structure (SE) was also determined using a force field of $\operatorname{CCSD}(\mathrm{T})$ quality, but the result was not satisfactory. One of the main goals of this paper is to try to explain the reason for this failure and to propose solutions. There are two obvious explanations: there is no isotopic substitution available for the fluorine atom. Furthermore, the boron atom is extremely close to the center of mass; in other words, the substitution ${ }^{11} \mathrm{~B} \rightarrow{ }^{10} \mathrm{~B}$ does not bring useful information. In conclusion, there are not enough data (i.e. rotational constants) available. There is one more reason: $\mathrm{BF}_{2} \mathrm{OH}$ is an oblate molecule and isotopic substitutions may induce large rotations of the principal axis system (PAS) that may amplify the errors. ${ }^{12}$ This point will be confirmed here. Finally, it is also possible that the large amplitude motion of the $\mathrm{OH}$ group hinders an accurate determination of the semiexperimental structure. This last point will be investigated here.
The semiexperimental (SE) structures of several molecules with a large amplitude motion have already been determined. In the case of molecules with a methyl group (propene, ${ }^{13}$ methyl formate, ${ }^{14}$ dimethyl ether, ${ }^{15}$ dimethyl sulfide ${ }^{16}$ ), the internal rotation does not seem to affect negatively the accuracy of the SE structure. For molecules with an $\mathrm{OH}$ group, the situation is more complicated. ${ }^{17}$ It was possible to obtain accurate SE structures for nitrous acid (syn and anti conformers), ${ }^{18,19}$ formic acid (syn and anti conformers $)^{20}$ as well as glycolaldehyde. ${ }^{17}$ On the other hand, for proline $^{21}$ and glycidol, ${ }^{17}$ the SE rotational constants of the OD species were found to be incompatible with the best structure. Finally, although accurate SE structures could be determined for ethanol (anti conformer) ${ }^{17}$ and nitric acid, ${ }^{22}$ there was obviously a problem: the rotation-vibration interaction constants ( $\alpha$-constants) of the lowest fundamental vibration could not be reproduced accurately by the $a b$ initio force field. It might lead us to think that it is due to the large amplitude vibration. However, the same problem is encountered in some rigid molecules such as $\mathrm{HCOCl}^{23}$ and vinyl fluoride. ${ }^{24}$ An alternative explanation is that the structure used to calculate the $a b$ initio force field is not accurate and might therefore lead to inaccuracies in some $\alpha$-constants. $\mathrm{BF}_{2} \mathrm{OH}$ is a favourable case to check this hypothesis because it is a rather small molecule; furthermore, it is planar.

In the present paper, after a short description of the experimental details, the spectra for the $\nu_{1}, v_{2}$ and $\nu_{3}$ bands are analyzed. The energy levels for the $1^{1}, 2^{1}$ and $3^{1}$ vibrational states as well as the $\left\{6^{1}, 7^{1}, 8^{1}, 9^{1}\right\}$ and $\left\{4^{1}, 7^{1} 9^{1}, 6^{1} 7^{1}, 9^{2}, 6^{1} 9^{1}\right\}$ resonating states are computed, and the molecular parameters are subsequently determined. Then, the accuracy of the Born-Oppenheimer $a b$ initio structure is confirmed. Next, the quality of the ab initio anharmonic force field is evaluated followed by a discussion of the accuracy of the rovibrational corrections. Finally, the difficulties inherent in the determination of the semiexperimental structure are examined, and the $\mathrm{SE}$ structure is determined using the method of mixed estimation. 


\section{Experimental details}

The details of the synthesis of the enriched isotopologues ${ }^{10} \mathrm{~B}(92.4 \%)$ and ${ }^{11} \mathrm{~B}(99 \%)$ of $\mathrm{BF}_{2} \mathrm{OH}$ and the recording of the high resolution FTIR spectra are given in ref. 8. The resolution (1/maximum optical path difference) was adjusted to $2.4 \times$ $10^{-3} \mathrm{~cm}^{-1}$, and the precision and wavenumber accuracy are better than $0.5 \times 10^{-3}$ and better than $1 \times 10^{-3} \mathrm{~cm}^{-1} .8$

As usual, water lines ${ }^{25}$ were observed as impurities in both spectral regions. In addition, the analysis was complicated in the $1430-1470 \mathrm{~cm}^{-1}$ region by the presence of lines from the strong $\nu_{3}$ perpendicular band of the ${ }^{11} \mathrm{BF}_{3}$ impurity centered at $1453.98 \mathrm{~cm}^{-1} .^{26}$

\section{Analysis}

In the present infrared study it was possible to perform the first high resolution analysis of the $\nu_{2}$ and $\nu_{3}$ bands together with the first identification of the $\nu_{1}$ band of ${ }^{11} \mathrm{~B}$.

During this study, the ground state energy levels were computed using the accurate ground state constants derived in ref. 4 and, as a model, a Watson A-type Hamiltonian written in $\mathrm{I}^{\mathrm{r}}$ representation. ${ }^{27}$ For symmetry reasons, $\nu_{1}, \nu_{2}$ and $\nu_{3}$ are, in principle, hybrid bands with both A- and B-type transitions. Fig. 1 and 2 give overviews of the $\nu_{1}$ band and of the $\nu_{2}$ and $\nu_{3}$ bands, respectively. In fact, the $v_{1}$ and $\nu_{2}$ are mainly pure A-type bands while both A- and B-type transitions were observed for the $\nu_{3}$ band. For these three bands the $\mathrm{Q}$ branches are rather narrow, while in the $\mathrm{P}$ and $\mathrm{R}$ branches, lines are grouped into clusters, and each "s" cluster gathers together transitions $\left[J, K_{a}, K_{c}\right]-\left[J \pm 1, K_{a}, K_{c} \pm 1\right]$, involving the same value of " $s$ " with

$$
s=2 J-K_{c}
$$

For these unresolved doublet transitions, ${ }^{8} \mathrm{~J}$ is the rotational quantum number and $K_{a}, K_{c}$ are pseudo quantum numbers that

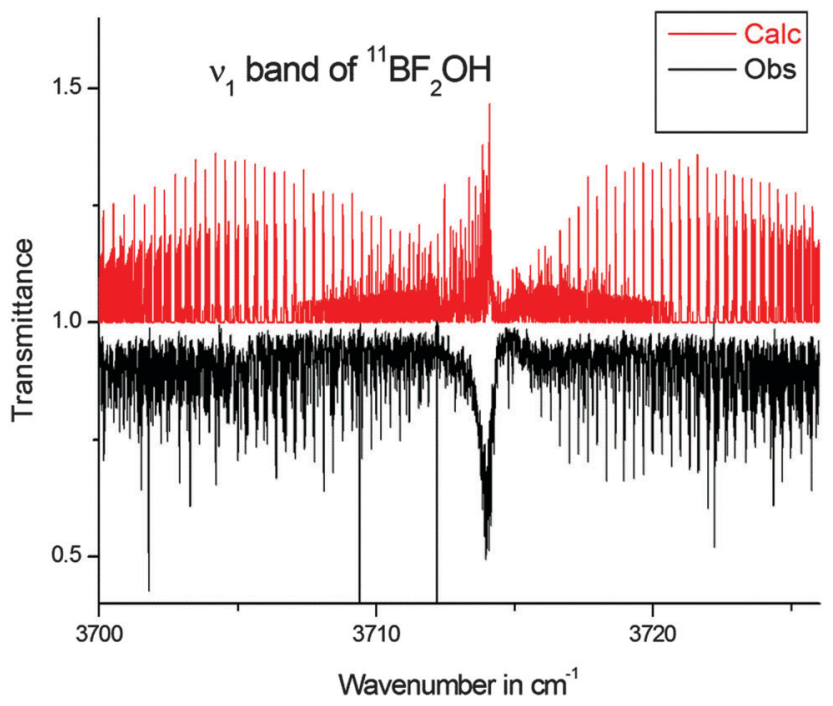

Fig. 1 The A-type $\nu_{1}$ band of $\mathrm{BF}_{2} \mathrm{OH}$.

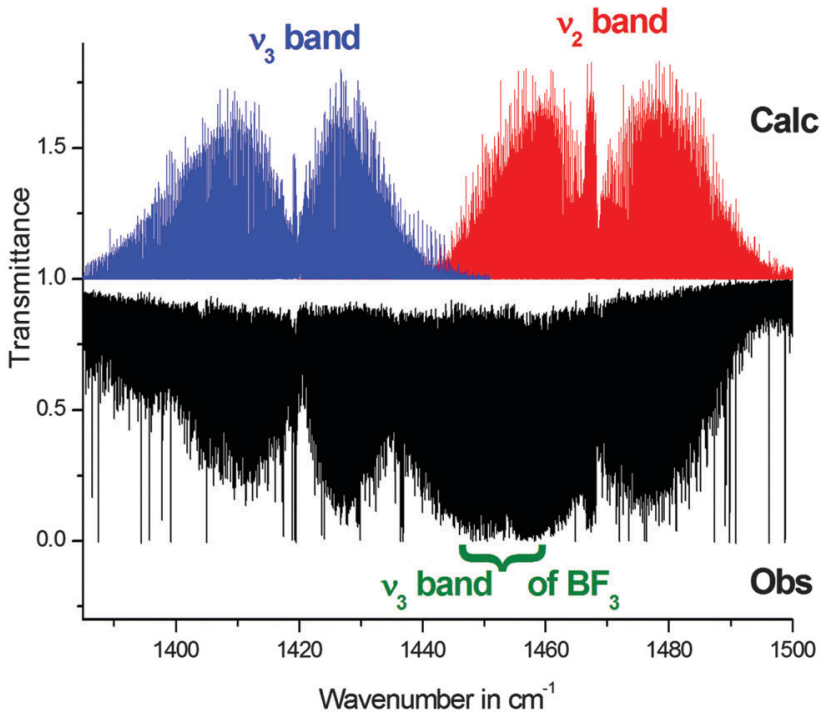

Fig. 2 Overview of the $v_{2}$ and $v_{3}$ bands of $\mathrm{BF}_{2} \mathrm{OH}$. In this spectral region, impurity lines from the $v_{3}$ band of $\mathrm{BF}_{3}$ are also clearly observable.

correlate with the $K=|k|$ quantum number about the $a$ and $c$ axes in the prolate and oblate symmetric top limits, respectively.

The first identifications were initiated by taking advantage of line regularities from one cluster to another one in the $\mathrm{P}$ and $\mathrm{R}$ branches. Once a few lines were assigned, the energy levels of the various upper vibrational states were computed by adding to the observed line positions the computed ground state energies. These first sets of energy levels were included in a least squares fit, and a first set of vibrational energies and upper state rotational constants were determined for the $1^{1}, 2^{1}$ and $3^{1}$ vibrational states. With these first sets of constants it was possible to make better predictions and hence to assign new lines. The process was repeated until it was no longer possible to perform new assignments.

For the $v_{2}$ band, the assignment is rather complete, because the band is only weakly perturbed. On the other hand, the $v_{3}$ band is highly perturbed, and this is why the analysis concerns only several series involving low $K_{a}$ values.

For the $\nu_{1}$ band, the assignments are restricted to the identification of the " $s$ " clusters in the $\mathrm{P}$ and $\mathrm{R}$ branches (see eqn (1)), with $s \leq 33$, and no detailed and faithful information can be obtained on the rotational structure within each cluster in the $3600-3800 \mathrm{~cm}^{-1}$ region. This limitation is because the Doppler line width of each individual line $\left(\sim 0.028 \mathrm{~cm}^{-1}\right.$ at $296 \mathrm{~K}$ ) in each cluster is already of the order of magnitude of the separation between two adjacent lines belonging to the same cluster. Furthermore, we presume that the $\nu_{1}$ band is perturbed, and this complicated further the analysis.

\section{Energy level calculations}

\subsection{Theoretical model}

Several vibration-rotation resonances were accounted for, depending on the resonating states considered. A brief description of the 
Hamiltonian models that we had to use to perform these calculations is given in the Appendix. As in ref. 9 the Euler angle $\theta$, which could not be determined, was set at zero.

\subsection{The $1^{1}, 2^{1}$ and $3^{1}$ states}

For the $2^{1}$ state and $3^{1}$ vibrational states we present two calculations. The first one was done assuming that these states are isolated, while the second one accounts for the C-type Coriolis resonance which couples together the $2^{1}$ and $3^{1}$ energy levels. Among the set of $2^{1}$ and $3^{1}$ measured energy levels, only those which can be considered as "less perturbed" by resonances involving dark states were considered in the least squares fit calculations. The parameters (vibrational energies, rotational constants and C-type interacting parameter) resulting from these computations are quoted together with their associated uncertainties in Table 2 . The $A$ rotational constants proved to be non-determinable and were maintained fixed at the value proposed by Breidung et al. ${ }^{4}$ Table S1 of the ESI $\dagger$ gathers details of the energy level calculations in terms of standard deviations and statistical analyses. It appeared that these two calculations (coupled and uncoupled) differ only marginally in terms of the quality of the fit. This outcome is expected because the resonances involving $2^{1}$ and $3^{1}$ energy levels with those of unidentified dark states were not considered during these two calculations.

Finally, we performed an energy calculation for the $1^{1}$ state. As input for the least squares fit calculation, we used the "pseudo" $1^{1}$ energy levels obtained from the identification of the " $s$ " clusters in the P and R branches (see eqn (1)). Among the resulting parameters generated during this fit (see Table 2) only the vibrational energy $\left(E_{1}=3714.1142 \mathrm{~cm}^{-1}\right)$ has a physical meaning. Indeed, the $A, B$ and $C$ rotational constants which have clearly unrealistic values are quoted because these parameters were used to model the $\nu_{1}$ band presented in Fig. 1.

\subsection{The $\left\{6^{1}, 7^{1}, 8^{1}, 9^{1}\right\}$ and $\left\{4^{1}, 7^{1} 9^{1}, 6^{1} 7^{1}, 9^{2}, 6^{1} 9^{1}\right\}$ resonating states}

The experimental energy levels of $7^{1}, 8^{1}$ and $9^{1}$ (resp. of those $4^{1}, 7^{1} 9^{1}$ and $9^{2}$ ) resulting from the analysis performed in ref. 8 (resp. ref. 9) were introduced in a least squares fit calculation to determine the parameters (band centers, rotational and interacting constants, together with, eventually, torsional constants) for the $\left\{6^{1}, 7^{1}, 8^{1}, 9^{1}\right\}$ (resp. $\left\{4^{1}, 7^{1} 9^{1}, 6^{1} 7^{1}, 9^{2}, 6^{1} 9^{1}\right\}$ ) resonating states.

The goal of these new calculations was to account explicitly for the Fermi, or A-type, B-type and C-type Coriolis resonances predicted by the $a b$ initio calculations.

The parameters (vibrational energies, rotational constants and interacting parameters) resulting from this computation are quoted together with their associated uncertainties in Tables 3-5.

Let us mention that the $6^{1}$ band center was fixed at $479.17 \mathrm{~cm}^{-1}$ which corresponds to the infrared broad $\mathrm{Q}$ branch structure observed in the FTIR spectra recorded at Wuppertal. ${ }^{8}$ Also, the zero order term involved in the expansion of the Fermi operator coupling the $4^{1} \Leftrightarrow 9^{2}$ interacting states was maintained fixed at the value predicted by the $a b$ initio calculation:

$$
{ }^{99,4} F_{0}=27.1 \mathrm{~cm}^{-1}
$$

The results of these new energy level calculations are satisfactory (standard deviation of $0.30 \times 10^{-3} \mathrm{~cm}^{-1}$ and $0.82 \times 10^{-3} \mathrm{~cm}^{-1}$, respectively) and do not differ in quality from those achieved during our previous calculations (see details of the statistical analysis of the results in Table 5 in ref. 8 and Table 3 in ref. 9).

Table 2 Hamiltonian constants (in $\mathrm{cm}^{-1}$ ) for the $1^{1}, 2^{1}$ and $3^{1}$ vibrational states of ${ }^{11} \mathrm{BF}_{2} \mathrm{OH}$ assumed isolated and for the $\left\{2^{1}, 3^{1}\right\}$ interacting vibrational states $^{a}$

\begin{tabular}{lllll}
\hline & $E_{\mathrm{v}}$ & $A$ & $B$ & $C$ \\
\hline $0^{b}$ & & 0.3442527640 & 0.3368801590 & 0.1699552140 \\
$1^{1}$ & $3714.1143(8)$ & $0.3437337(170)$ & $0.3359471(285)$ & $0.16984120(148)$ \\
$2^{1}$ & $1468.2741(48)$ & $0.3427690(200)$ & $0.3357875(320)$ & $0.17047311(780)$ \\
$3^{1}$ & $1419.1696(34)$ & $0.343047867^{c}$ & $0.3365527(520)$ & $0.16787843(700)$ \\
$2^{1}$ & $1468.2733(22)$ & $0.34277878(790)$ & $0.3357541(130)$ & $0.168557(240)$ \\
$3^{1}$ & $1419.1758(47)$ & $0.343047867^{c}$ & $0.3365758(670)$ & $0.169788(240)$
\end{tabular}

${ }^{a}$ All centrifugal distortion constants are fixed to the ground state values. ${ }^{b}$ Fixed to the ground state values. ${ }^{4}{ }^{c}$ For $3^{1}$ the A rotational constant is maintained at the value predicted by Breidung et al. ${ }^{4 d}$ C-type Coriolis constant.

Table 3 Hamiltonian constants (in $\mathrm{cm}^{-1}$ ) for the $\left\{6^{1}, 7^{1}, 8^{1}, 9^{1}\right\}$ interacting vibrational states of ${ }^{11} \mathrm{BF}_{2} \mathrm{OH}$

\begin{tabular}{lllll}
\hline & $6^{1}$ & $7^{1}$ & $8^{1}$ & $9^{1}$ \\
\hline$E_{\mathrm{V}}$ & $479.17^{a}$ & $446.55171(7)$ & $684.15840(7)$ & $522.86815(5)$ \\
$A$ & $0.3459420(900)$ & $0.344720533(186)$ & $0.343991965(110)$ & $0.343258360(600)$ \\
$B$ & $0.335897(141)$ & $0.337393954(636)$ & $0.336966965(240)$ & $0.336529392(380)$ \\
$C$ & $0.1690340(173)$ & $0.170573446(520)$ & $0.170199092(58)$ & $0.169986115(190)$ \\
$\Delta_{\mathrm{K}} \times 10^{6}$ & $b$ & $0.354948(940)$ & $0.361381(230)$ & $0.351405(710)$ \\
$\Delta_{\mathrm{JK}} \times 10^{6}$ & $b$ & $b$ & $0.208940(420)$ & $0.1049458(280)$ \\
$\Delta_{\mathrm{J}} \times 10^{6}$ & $b$ & $0.204124(910)$ & $0.172065(150)$ & $0.2004195(110)$ \\
$\Delta_{\mathrm{K}} \times 10^{6}$ & $b$ & $0.19104(370)$ & $b$ & $0.174388(230)$ \\
$\Delta_{\mathrm{J}} \times 10^{7}$ & $b$ & $0.96250(540)$ & & $0.898740(630)$
\end{tabular}

${ }^{a}$ All other centrifugal distortion constants are fixed to the ground state values. ${ }^{4}{ }^{b}$ Fixed to the infrared observed broad structure (see text in ref. 8). 
Table 4 Interaction parameters (in $\mathrm{cm}^{-1}$ )

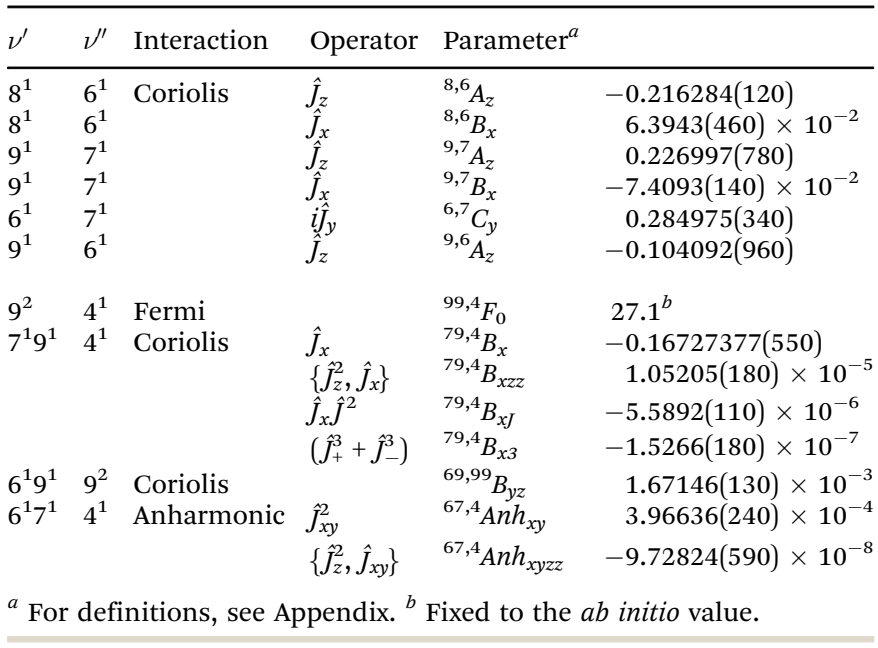

The values achieved during this work for the $h^{\text {TORS }}$ (torsional) and $h^{\text {Bend }}$ (bending) splitting parameters $\left(h^{\mathrm{TORS}}=2.60833(250) \times\right.$ $10^{-3} \mathrm{~cm}^{-1}$ and $h^{\mathrm{BEND}}=1.82179(270) \times 10^{-3} \mathrm{~cm}^{-1}$, see Table 5) do not differ significantly from those obtained in ref. 9 , when neglecting the Fermi resonance coupling $4^{1} \Leftrightarrow 9^{2}\left(h^{\text {TORS }}=\right.$ $2.54516(1000) \times 10^{-3} \mathrm{~cm}^{-1}$ and $h^{\mathrm{BEND}}=1.78523(100) \times$ $10^{-3} \mathrm{~cm}^{-1}$; see Table 8 in ref. 9). Clearly, the torsional splitting in the $4^{1}$ state is not due to the existence of the weak Fermi resonance coupling the $4^{1}$ and $9^{2}$ states.

The assigned lines are given in Table S2 of the ESI. $\dagger$

\section{Ab initio equilibrium structure}

The $a b$ initio equilibrium structure has been previously optimized with the coupled cluster method with single and double excitations ${ }^{28}$ and a perturbative treatment of connected triples, ${ }^{29} \operatorname{CCSD}(\mathrm{T})$, along with the correlation-consistent polarized valence $n$-tuple- $\zeta$ basis sets

$\$$ In the present study, the $\operatorname{CCSD}(\mathrm{T})$ calculations were performed with the MOLPRO program package developed by H.-J. Werner, P. J. Knowles, F. R. Manby, M. Schütz, P. Celani, G. Knizia, T. Korona, R. Lindh, A. Mitrushenkov, G. Rauhut, T. B. Adler, R. D. Amos, A. Bernhardsson, A. Berning, D. L. Cooper, M. J. O. Deegan, A. J. Dobbyn, F. Eckert, E. Goll, C. Hampel, A. Hesselmann, G. Hetzer, T. Hrenar, G. Jansen, C. Köppl, Y. Liu, A. W. Lloyd, R. A. Mata, A. J. May, S. J. McNicholas, W. Meyer, M. E. Mura, A. Nicklaß, P. Palmieri, K. Pflüger, R. Pitzer, M. Reiher, T. Shiozaki, H. Stoll, A. J. Stone, R. Tarroni and T. Thorsteinsson, MOLPRO, 2009. See also: H.-J. Werner, P. J. Knowles, G. Knizia, F. R. Manby and M. Schütz, WIREs Comput. Mol. Sci., 2012, 2, 242-253. The MP2 and B2PLYPD calculations were carried out by means of the GAUSSIAN09 program: M. J. Frisch, G. W. Trucks, H. B. Schlegel, G. E. Scuseria, M. A. Robb, J. R. Cheeseman, G. Scalmani, V. Barone, B. Mennucci, G. A. Petersson, H. Nakatsuji, M. Caricato, X. Li, H. P. Hratchian, A. F. Izmaylov, J. Bloino, G. Zheng, J. L. Sonnenberg, M. Hada, M. Ehara, K. Toyota, R. Fukuda, J. Hasegawa, M. Ishida, T. Nakajima, Y. Honda, O. Kitao, H. Nakai, T. Vreven, J. A. Montgomery, J. E. Peralta, F. Ogliaro, M. Bearpark, J. J. Heyd, E. Brothers, K. N. Kudin, V. N. Staroverov, T. Keith, R. Kobayashi, J. Normand, K. Raghavachari, A. Rendell, J. C. Burant, S. S. Iyengar, J. Tomasi, M. Cossi, N. Rega, J. M. Millam, M. Klene, J. E. Knox, J. B. Cross, V. Bakken, C. Adamo, J. Jaramillo, R. Gomperts, R. E. Stratmann, O. Yazyev, A. J. Austin, R. Cammi, C. Pomelli, J. W. Ochterski, R. L. Martin, K. Morokuma, V. G. Zakrzewski, G. A. Voth, P. Salvador, J. J. Dannenberg, S. Dapprich, A. D. Daniels, O. Farkas, J. B. Foresman, J. V. Ortiz, J. Cioslowski and D. J. Fox, GAUSSIAN09, Rev.C.01, 2010, Wallingford, CT.
(cc-pVnZ with $n=3,4) .{ }^{30}$ The inner-shell correlation was estimated with the second-order Møller-Plesset perturbation theory, MP2, ${ }^{31}$ and the Martin-Taylor (MT) basis set. ${ }^{32}$ To account for the electronegative character of the $\mathrm{F}$ and $\mathrm{O}$ atoms, the augmented cc-pVQZ ${ }^{33}$ basis set was used at the MP2 level. To investigate the structural effects of further basis set improvement (cc-pVQZ $\rightarrow$ cc-pV5Z), the cc-pV5Z basis set was employed at the MP2 level. The derived structure is expected to be accurate. However, to estimate its precision, we repeated the optimization using different schemes.

First, the augmented correlation-consistent polarized weighted core-valence $n$-tuple- $\zeta$, aug-cc-pwCV $n \mathrm{Z}$, basis sets ${ }^{34}$ with $n=\mathrm{D}, \mathrm{T}, \mathrm{Q}, 5$ were used, and all electrons were correlated (AE); consequently,

$$
r_{\mathrm{e}}^{\mathrm{BO}}(\mathrm{I})=r_{\mathrm{e}}\left[\mathrm{CCSD}(\mathrm{T}) \_\mathrm{AE} / \text { aug-cc-pwCV5Z }\right] .
$$

The cc-pwCVnZ basis sets were also used without the diffuse functions (aug),

$$
r_{\mathrm{e}}^{\mathrm{BO}}(\mathrm{II})=r_{\mathrm{e}}\left[\mathrm{CCSD}(\mathrm{T}) \_\mathrm{AE} / \mathrm{cc}-\text { pwCV5Z }\right] .
$$

The smaller basis sets, $n=\mathrm{D}, \mathrm{T}, \mathrm{Q}$, allow us to check the rate of convergence. The results are given in Table 6, and the details are given in Table S3 of the ESI. $\dagger$ It is interesting to note that the two types of basis sets with and without the aug functions converge towards the same limit.

The $r_{\mathrm{e}}^{\mathrm{BO}}$ structure was also estimated in the frozen core, FC, approximation using the cc-pV5Z and aug-cc-pV5Z basis sets and the $\operatorname{CCSD}(\mathrm{T})$ method. The core-core and core-valence correlation is missing from this treatment. Therefore, the correlation corrections were estimated as differences between the values from $\mathrm{AE}$ and $\mathrm{FC}$ results at the $\mathrm{CCSD}(\mathrm{T})$ level using the cc-pwCVTZ, cc-pwCVQZ and cc-pwCV5Z basis sets, as well as at the MP2 level with cc-pwCVQZ and MT basis sets (see Table S4 of the ESI $\dagger$ ). Consequently, the $r_{\mathrm{e}}^{\mathrm{BO}}$ structures could be estimated by the following alternative schemes:

$$
\begin{aligned}
r_{\mathrm{e}}^{\mathrm{BO}}(\mathrm{III})= & r_{\mathrm{e}}\left[\mathrm{CCSD}(\mathrm{T}) \_\mathrm{FC} / \text { aug-cc-pV5Z }\right]+r_{\mathrm{e}}\left[\mathrm{CCSD}(\mathrm{T}) \_\mathrm{AE} / \mathrm{cc}-\mathrm{pwCV} 5 \mathrm{Z}\right] \\
& -r_{\mathrm{e}}\left[\mathrm{CCSD}(\mathrm{T}) \_\mathrm{FC} / \mathrm{cc}-\mathrm{pwCV} 5 \mathrm{Z}\right]
\end{aligned}
$$

and

$$
\begin{aligned}
r_{\mathrm{e}}^{\mathrm{BO}}(\mathrm{IV})= & r_{\mathrm{e}}\left[\mathrm{CCSD}(\mathrm{T}) \_\mathrm{FC} / \mathrm{cc}-\mathrm{pV} 5 \mathrm{Z}\right]+r_{\mathrm{e}}\left[\mathrm{CCSD}(\mathrm{T}) \_\mathrm{AE} / \text { aug-cc-pwCV5Z }\right] \\
& -r_{\mathrm{e}}\left[\mathrm{CCSD}(\mathrm{T}) \_\mathrm{FC} / \mathrm{cc}-\mathrm{pwCV} 5 \mathrm{Z}\right] .
\end{aligned}
$$

As seen in Table S4 of the ESI, $\dagger$ the core correlation correction is practically converged at the $\operatorname{CCSD}(\mathrm{T}) \_\mathrm{AE} / \mathrm{cc}-\mathrm{pwCVQZ}$ level. The MP2/cc-pwCVQZ level of theory also gives satisfactory results, the much smaller MT basis set giving results of comparable quality. Another interesting result is that the aug-cc-pV $n \mathrm{Z}$ and cc-pV $n \mathrm{Z}$ basis sets converge towards the same limit. For the above structures, the accuracy is not limited by the basis set convergence but by the approximate (perturbative) treatment of connected triples and the neglect of higher-order connected excitations in the coupled cluster method.

A further, cheaper scheme was also utilized. The structure was computed with the smaller cc-pwCVTZ basis set and the $\operatorname{CCSD}(\mathrm{T}) \_\mathrm{AE}$ method, and the effect of further basis set enlargement, 
Table 5 Hamiltonian constants for the $\left\{4^{1}, 7^{1} 9^{1}, 6^{1} 7^{1}, 9^{2}, 6^{1} 9^{1}\right\}$ resonating states of ${ }^{11} \mathrm{BF} F_{2} \mathrm{OH}$ (all constants are in $\mathrm{cm}^{-1}$, and the quoted errors are for one standard deviation)

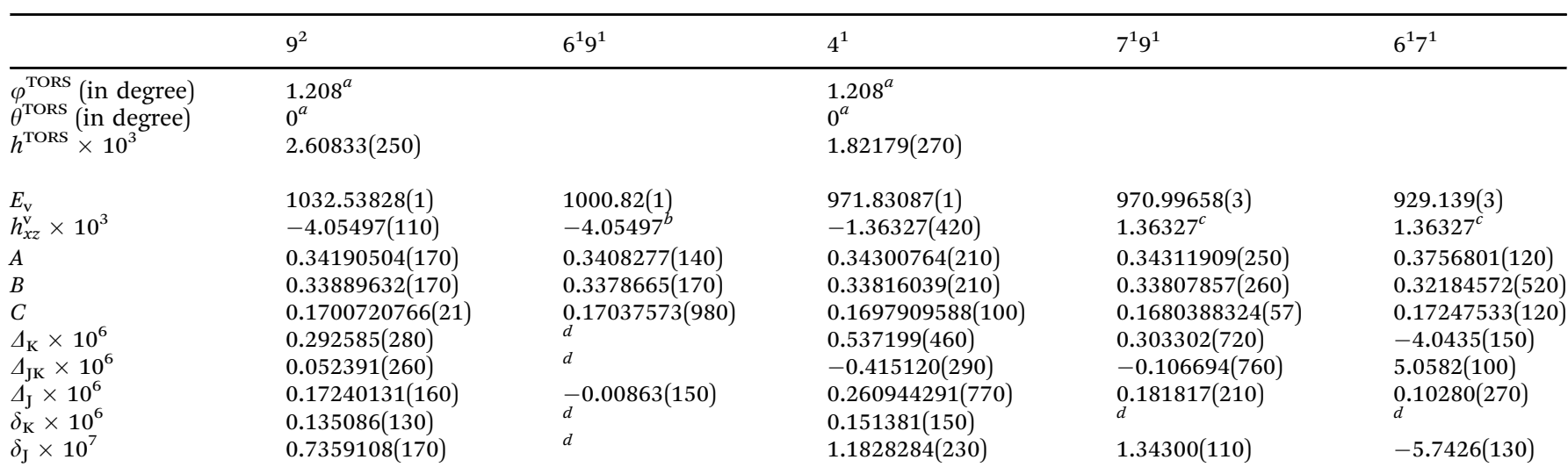

${ }^{a}$ The angles $\varphi^{\text {TORS }}$ and $\theta^{\text {TORS }}$ in degree were maintained at the values determined in ref. $8 .{ }^{b}$ Fixed to the $9^{2}$ value. ${ }^{c}$ Fixed to the $4^{1}$ value. ${ }^{d}$ All other centrifugal distortion constants are fixed to the ground state value. ${ }^{4}$

Table 6 Equilibrium structure of $\mathrm{BF}_{2} \mathrm{OH}$ (distances in $\AA$ and angles in degree)

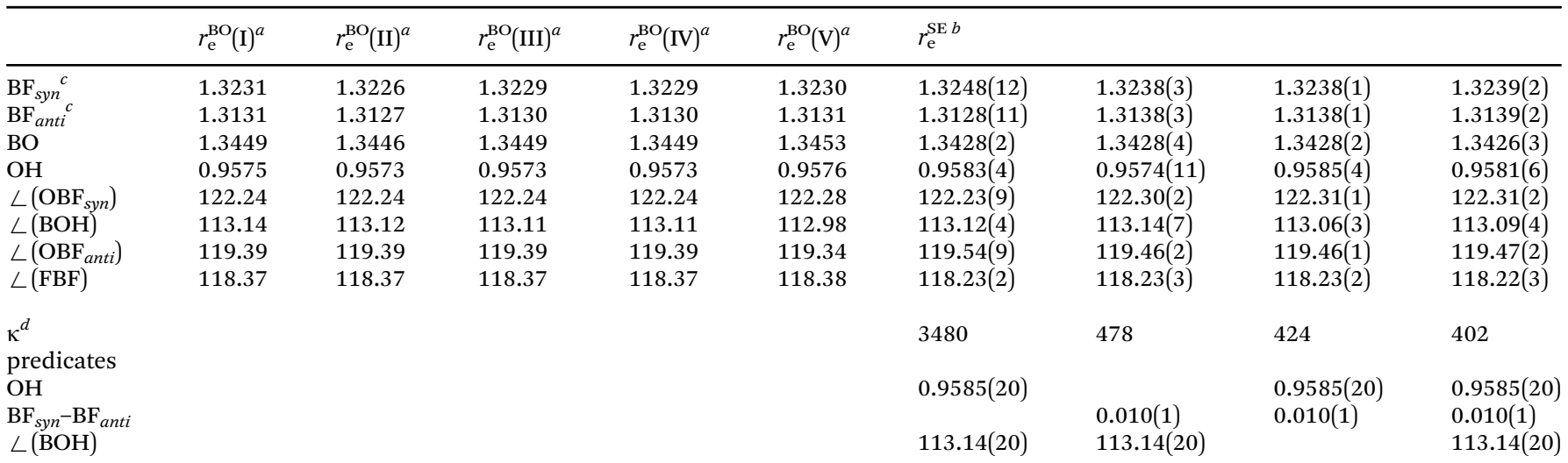

${ }^{a}$ For definitions, see eqn (3)-(6). ${ }^{b}$ For the definition of the predicates, see text. The best structure is given in the last column. ${ }^{c} \mathrm{~F}$ atom is in synperiplanar or antiperiplanar position with respect to the $\mathrm{OH}$ bond. ${ }^{d}$ Condition number of the fit.

cc-pwCVTZ $\rightarrow$ cc-pwCVQZ, was estimated at the MP2 level. In other words, the $r_{\mathrm{e}}^{\mathrm{BO}}$ parameters are obtained using the following equation:

$$
\begin{aligned}
r_{\mathrm{e}}^{\mathrm{BO}}(\mathrm{V})= & r_{\mathrm{e}}\left[\mathrm{CCSD}(\mathrm{T}) \_\mathrm{AE} / \mathrm{cc}-\mathrm{pwCVTZ}\right]+r_{\mathrm{e}}[\mathrm{MP} 2(\mathrm{AE}) / \mathrm{cc}-\mathrm{pwCVQZ}] \\
& -r_{\mathrm{e}}[\mathrm{MP} 2(\mathrm{AE}) / \mathrm{cc}-\mathrm{pwCVTZ}] .
\end{aligned}
$$

The basic assumption of eqn (7) is that the correction due to basis set enlargement, cc-pwCVTZ $\rightarrow$ cc-pwCVQZ, is small and can, therefore, be estimated at the MP2 level. This approximation was investigated in several previous studies by us and was found to be reliable. Here, again it is confirmed that this approximation gives results which are accurate enough. ${ }^{35-38}$

In conclusion, when the basis set used is large enough, there is no need to use the augmented functions, and the MT basis set seems to be accurate enough to estimate the core correlation. In other words, an accurate structure may be obtained.

\section{Semiexperimental structure}

\subsection{Anharmonic force field}

The anharmonic force field has been previously calculated at the CCSD(T)_AE/TZ2Pf level of theory. ${ }^{4}$ The theoretical fundamental wavenumbers of the different isotopologues were found to be in good agreement with their experimental counterparts. Furthermore, the ab initio quartic centrifugal distortion constants are also in good agreement with the experimental ones. This agreement is an indication that the $a b$ initio force field is likely to be accurate. Generally, it is more difficult to compute an accurate $a b$ initio harmonic force field than a cubic one. ${ }^{39}$ We have tried to improve the $a b$ initio harmonic force field by fitting at the best equilibrium structure, $r_{\mathrm{e}}^{\mathrm{BO}}(\mathrm{I})$, the experimental quartic centrifugal distortion constants and the harmonic frequencies derived from the experimental fundamental frequencies and the anharmonicity corrections $\omega_{i}-v_{i}$. No significant improvement was found. This fact confirms that the $a b$ initio harmonic force field is probably indeed accurate.

\subsection{Rovibrational corrections \$}

There is little difficulty obtaining accurate ground state rotational constants. Therefore, the accuracy of the derived SE structure depends on the accuracy of the rovibrational corrections. They were calculated at the $\operatorname{CCSD}(\mathrm{T}) \_\mathrm{AE} / \mathrm{TZ} 2 \mathrm{Pf}$ level of theory. ${ }^{4}$ As a first check, they were also calculated with the Kohn-Sham density 
functional theory (DFT) ${ }^{40}$ using the B2PLYPD double hybrid exchange-correlation functional with long range dispersion correction, ${ }^{41}$ along with the $6-311+\mathrm{G}(3 \mathrm{df}, 2 \mathrm{pd})$ basis set. The results of this lower-level calculation give a first indication that the rovibrational correction is indeed reliable. Indeed, for the unperturbed state $5^{1}$, the values at the B2PLYPD/6-311+G(3df,2pd) level of theory are (in MHz) $\alpha_{5}^{A}=20.9, \alpha_{5}^{B}=19.8$ and $\alpha_{5}^{C}=10.6$. These values are close to the CCSD(T)_AE/TZ2Pf ones; see Table 7 .

As a further check, it is tempting to compare the experimental $\alpha$-constants to the ones computed from the ab initio cubic force field. However, even when the rotational constants of all fundamental states have been determined, which is often an extremely difficult task, the experimental $\alpha$-constants are different from the $a b$ initio ones. The main cause is that a vibrational state is rarely isolated and, therefore, the derived rotational constants depend on the interactions that have been taken into account; see Section 4 . There are numerous interactions between the fundamental states of ${ }^{11} \mathrm{BF}_{2} \mathrm{OH}$. As shown in Table 1, there is no isolated state. However, although the harmonic frequencies $\omega_{5}$ and $2 \omega_{7}$ are almost degenerate, the Fermi interaction $v_{5} / 2 v_{7}$ seems to be negligible due to the almost vanishing cubic constant $\varphi_{577}=-0.8 \mathrm{~cm}^{-1}$. As a consequence, there is a very good agreement between the experimental and computed $\alpha$ 's for the $5^{1}$ state. There is a very strong $c$-type interaction between the states $6^{1}$ and $7^{1}$. However, it is still possible to determine the rotational constants from the low- $J$ transitions neglecting this interaction. The corresponding experimental $\alpha^{C}$-constants are in good agreement with the computed ones; the same holds for the states $3^{1}, 4^{1}, 5^{1}, 8^{1}$ and $9^{1}$ for which there is no significant interaction affecting the $C$ rotational constant (see Table 7). On the other hand, when the Coriolis interaction is taken into account, the agreement is much worse. The state $9^{1}$, which is in weak Coriolis interaction with the states $6^{1}$ and $7^{1}$, allows us to see the effect of the interactions on the $\alpha$-constants. They may be determined from the state $9^{1}$ neglecting the interactions or taking them into

Table 7 Rotation-vibration interaction constants $(\mathrm{MHz})$ for ${ }^{11} \mathrm{BF}_{2} \mathrm{OH}$

\begin{tabular}{|c|c|c|c|c|c|c|c|}
\hline \multirow[b]{2}{*}{ Mode } & \multirow[b]{2}{*}{ Interaction $^{a}$} & \multicolumn{2}{|l|}{$\alpha_{i}^{A}$} & \multicolumn{2}{|l|}{$\alpha_{i}^{B}$} & \multicolumn{2}{|l|}{$\alpha_{i}^{C}$} \\
\hline & & Exp. $^{b}$ & $\mathrm{Cal}^{c}{ }^{c}$ & Exp. $^{b}$ & $\mathrm{Cal}^{c}{ }^{c}$ & Exp. $^{b}$ & $\mathrm{Cal}^{c}{ }^{c}$ \\
\hline 1 & No & 15.6 & 3.9 & 28.0 & 12.8 & 3.4 & 4.1 \\
\hline \multirow[t]{2}{*}{2} & No & 44.5 & 46.3 & 32.8 & 33.1 & -15.5 & -20.6 \\
\hline & $\zeta_{23}{ }^{c}$ & 44.2 & 46.3 & 33.8 & 33.1 & 41.9 & 23.0 \\
\hline \multirow[t]{2}{*}{3} & No & - & 36.1 & 9.8 & 44.2 & 62.3 & 67.3 \\
\hline & $\zeta_{23}{ }^{c}$ & - & 36.1 & 9.1 & 44.2 & 5.0 & 23.7 \\
\hline \multirow[t]{2}{*}{4} & No & 38.1 & -8.6 & -37.4 & -8.3 & 3.8 & 3.7 \\
\hline & $d$ & 37.3 & - & -38.4 & - & 4.9 & - \\
\hline 5 & No & 19.7 & 19.4 & 19.1 & 19.3 & 10.2 & 10.0 \\
\hline \multirow[t]{2}{*}{6} & $\mathrm{No}^{e}$ & -10.0 & -15.1 & -9.2 & -6.9 & -49.7 & -50.0 \\
\hline & $\zeta_{67}^{c}$ & -9.8 & -15.1 & -9.1 & -6.9 & 22.7 & 3.9 \\
\hline \multirow[t]{2}{*}{7} & No & 6.2 & 4.8 & -12.8 & -18.8 & 56.1 & 55.8 \\
\hline & $\zeta_{67}{ }^{c}$ & 6.0 & 4.8 & -12.9 & -18.8 & -16.3 & 1.9 \\
\hline 8 & No & 1.0 & -0.1 & -3.2 & -4.0 & -7.3 & -7.5 \\
\hline \multirow[t]{2}{*}{9} & No & 2.0 & 13.3 & 8.6 & 3.7 & -0.9 & -0.8 \\
\hline & $f$ & 29.8 & - & 10.5 & - & -0.9 & - \\
\hline
\end{tabular}

${ }^{a}$ See text and Table $1 .{ }^{b}$ This work and ref. 8 and 9. ${ }^{c} \operatorname{CCSD}(\mathrm{T}) \_\mathrm{AE} /$ TZ2Pf value. ${ }^{d}$ See text and Table $4 .{ }^{e}$ Note that there is a good agreement for $\alpha_{6}^{A}+\alpha_{6 \cdot}^{B}{ }^{f}$ See text and Tables 3 and 4 .
Table 8 Different ways to obtain the rotation-vibration interaction constants $^{a}$ (in $\mathrm{MHz}$ ) of the state $\nu_{9}=1$

\begin{tabular}{|c|c|c|c|}
\hline & $\alpha_{9}^{A}$ & $\alpha_{9}^{B}$ & $\alpha_{9}^{C}$ \\
\hline From the $\operatorname{CCSD}(\mathrm{T}) \_\mathrm{AE} / \mathrm{TZ2Pf}$ force field & 13.292 & 3.681 & -0.808 \\
\hline From $9^{1}$ without interaction & 1.997 & 8.649 & -0.932 \\
\hline From $8^{1}+9^{1}$ and $8^{1}$ & 4.857 & 10.033 & -0.314 \\
\hline From $9^{1}$ with interactions ${ }^{b}$ & 29.885 & 10.446 & -0.926 \\
\hline From $9^{1}$ with interactions ${ }^{c}$ & 29.805 & 10.527 & -0.924 \\
\hline
\end{tabular}

${ }^{a}$ The statistical uncertainty is only a few kHz. ${ }^{b}$ Coriolis interactions with $6^{1}$ and $7^{1} .{ }^{c}$ Coriolis interactions with $6^{1}, 7^{1}$ and $8^{1}$.

account. It is also possible to obtain them from the states $8^{1}+$ $9^{1}$ and $8^{1}$. The results are given in Table 8 and confirm that the $\alpha$-constants may vary considerably.

Another way to check the accuracy of the rovibrational corrections is to compare the experimental ground state rotational constants with those derived from the best $a b$ initio structure, $r_{\mathrm{e}}^{\mathrm{BO}}(\mathrm{I})$, and the $a b$ initio rovibrational corrections. A still simpler and more powerful test is to look at the equilibrium inertial defects calculated from the semiexperimental equilibrium rotational constants. Ideally, they should be zero because the molecule is planar but, in most cases, they slightly differ from zero because of a systematic error in the rovibrational corrections. The results are shown in Table 9. It is obvious that there is a problem with the $A$ and $B$ rotational constants of the deuterated species because their residual, which is expected to be mainly systematic, is significantly different from that of the other isotopologues. Likewise, the semiexperimental inertial defect of the deuterated species has a sign opposite to that of the other species. Such a problem was expected and easy to explain. ${ }^{12}$ The errors of the semiexperimental constants $A$ and $B$ of the deuterated species are of similar magnitude but of opposite sign, whereas their sum is almost the same for all species. It is due to a large rotation of the principal axis system (PAS) upon isotopic substitution that amplifies the errors of the rovibrational corrections, a typical difficulty of oblate tops. Fig. 3 clearly shows that there is an axis switching when going from $\mathrm{BF}_{2} \mathrm{OH}$ to $\mathrm{BF}_{2} \mathrm{OD}$. It is also important

Table 9 Semiexperimental rotational constants and their difference from the $a b$ initio equilibrium ones (in $\mathrm{MHz}$ ) and semiexperimental inertial defects (in $u \AA^{2}$ )

\begin{tabular}{lllllll}
\hline & ${ }^{11} \mathrm{BF}_{2} \mathrm{OH}$ & ${ }^{10} \mathrm{BF}_{2} \mathrm{OH}$ & ${ }^{11} \mathrm{BF}_{2} \mathrm{OD}$ & ${ }^{10} \mathrm{BF}_{2} \mathrm{OD}$ & ${ }^{11} \mathrm{BF}_{2}{ }^{18} \mathrm{OH}^{10}{ }^{10} \mathrm{BF}_{2}{ }^{18} \mathrm{OH}$ \\
\hline$A_{\mathrm{e}}^{\mathrm{SE} a}$ & 10370.30 & 10370.53 & 10334.05 & 10334.11 & 10241.76 & 10241.75 \\
$B_{\mathrm{e}}^{\mathrm{SE}}$ & 10136.86 & 10136.96 & 9446.32 & 9446.31 & 9543.99 & 9544.00 \\
$C_{\mathrm{e}}^{\mathrm{SE} a}$ & 5126.15 & 5126.26 & 4935.06 & 4935.07 & 4940.37 & 4940.37 \\
$\Delta A^{b}$ & 4.04 & 4.05 & 2.03 & 1.99 & 3.23 & 3.21 \\
$\Delta B^{b}$ & 3.14 & 3.18 & 5.15 & 5.14 & 3.97 & 3.97 \\
$\Delta C^{b}$ & 1.82 & 1.85 & 1.80 & 1.79 & 1.90 & 1.90 \\
$\Delta A+\Delta B$ & 7.18 & 7.23 & 7.18 & 7.13 & 7.19 & 7.19 \\
$\Delta_{\mathrm{e}}{ }^{c}$ & -0.0006 & -0.0009 & 0.0014 & 0.0014 & -0.0017 & -0.0018 \\
$\delta A^{d}$ & -0.003 & -0.015 & -1.762 & -1.808 & -0.010 & -0.025 \\
$\delta B^{d}$ & -0.028 & 0.009 & 1.757 & 1.745 & -0.026 & -0.016 \\
$\delta C^{d}$ & 0.022 & 0.048 & 0.010 & -0.005 & 0.072 & 0.078
\end{tabular}

${ }^{a}$ Semiexperimental equilibrium rotational constants. ${ }^{b}$ Difference between the semiexperimental value and the value calculated from the $r_{\mathrm{e}}^{\mathrm{BO}}(\mathrm{I})$ structure from Table $6 .{ }^{c}$ Semiexperimental equilibrium inertial defect. ${ }^{d}$ Residuals of the fit, last column of Table 6. 


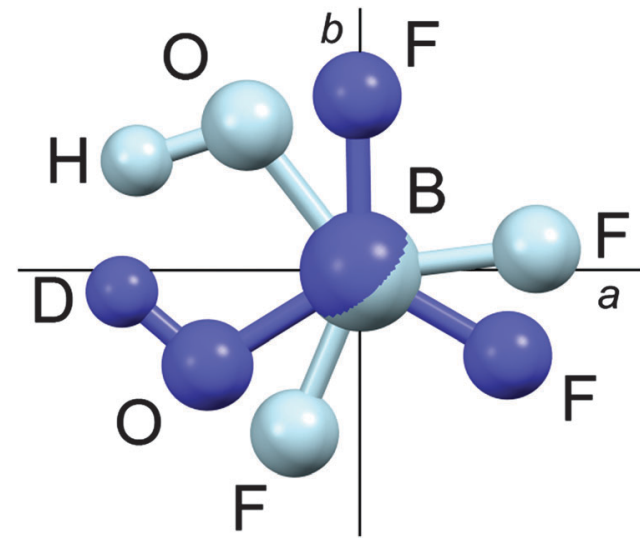

Fig. $3{ }^{11} \mathrm{BF}_{2} \mathrm{OH}$ and ${ }^{11} \mathrm{BF}_{2} \mathrm{OD}$ in their superposed principal axis systems.

to notice that the equilibrium inertial defect is much worse when any computed $\alpha$-constants are replaced by their experimental values.

\subsection{Determination of the structure}

There is no isotopic substitution available for fluorine. The boron atom is close to the center of mass, $a\left({ }^{11} \mathrm{~B}\right)=0.019 \AA$ and $b\left({ }^{11} \mathrm{~B}\right)=-0.034 \AA$; thus, the substitution ${ }^{11} \mathrm{~B} \rightarrow{ }^{10} \mathrm{~B}$ does not bring any new information. Furthermore, we have seen in the previous section that the $A$ and $B$ rotational constants of the deuterated species are affected by a rather large systematic error. Therefore, the available rotational constants do not allow us to determine a complete structure. To overcome this difficulty, the method of mixed regression may be used. ${ }^{42-44}$ This method, also called the predicate method, uses simultaneously equilibrium moments of inertia and bond lengths and bond angles from high-level quantum chemical calculations in the structure fitting. However, it is useful for large molecules only if reliable predicates may be estimated without using the expensive $\operatorname{CCSD}(\mathrm{T})$ method. Actually, it is known that the $\mathrm{OH}$ bond length can be estimated at the MP2 level using either the cc-pVTZ or the cc-pVQZ basis sets with an uncertainty less than $0.002 \AA^{45}$ On the other hand, the prediction of an accurate CF bond length is difficult. Nevertheless, it is easy to obtain an accurate value of the difference $r\left(\mathrm{CF}_{\text {syn }}\right)-r\left(\mathrm{CF}_{\text {anti }}\right)$ at the MP2/cc-pVQZ level; see Table $\mathrm{S} 1$ of the ESI. $\dagger$ Finally, the bond angles may be estimated at the MP2/6-311+G(3df,2pd) level of theory with an uncertainty of about $0.2^{\circ} .^{46}$ Different combinations of predicates were tried. A fit with three predicate values, $[r(\mathrm{OH})$, $r\left(\mathrm{BF}_{\text {syn }}\right)-r\left(\mathrm{BF}_{\text {anti }}\right)$ and $\left.\angle(\mathrm{BOH})\right]$, gives extremely good results; see Table 8. However, it is also possible to obtain a very satisfactory fit with only two predicate values as shown in Table 6. Yet, it has to be noted that, when $r\left(\mathrm{BF}_{\text {syn }}\right)-r\left(\mathrm{BF}_{\text {anti }}\right)$ is not used as a predicate, the fit is ill-conditioned with a large condition number, high correlation between the parameters and larger standard errors for the parameters. This result is simply due to the fact that there is not enough information to accurately determine the position of the fluorine atoms. On the other hand, the information given by the two predicates $r(\mathrm{OH})$ and $\angle(\mathrm{BOH})$ is somewhat redundant.
Obviously, the predicates play a leading role in increasing the accuracy of the parameters, but it is possible to check their influence by reducing their weight. In the particular case of $\mathrm{BF}_{2} \mathrm{OH}$, it does not significantly modify the parameters, but it increases their standard deviation as well as the condition number. Actually, the best guaranty of the compatibility of the predicates with the semiexperimental moments of inertia is an analysis of the residuals. The best semiexperimental structure is given in the last column of Table 6 .

\section{Conclusions}

The $a b$ initio calculation of the anharmonic force field and the analysis of the high-resolution infrared spectrum shows that almost all fundamental states are perturbed, even the lowest one. The only exception is the $5^{1}$ state which does not appear to be perturbed although it is in Fermi resonance with the extremely close $7^{2}$ state. This lack of mixing is due to the fact that the cubic force constant $\varphi_{577}$ is vanishingly small. When the perturbation is small and can thus be neglected, there is a satisfactory agreement between the experimental rotationvibration interaction constants and the values calculated from the force field. On the other hand, when the perturbations are taken into account in the analysis of the experimental spectra, the agreement becomes disappointing. This difficulty is rather frequent, $\mathrm{HCOOH}$ being another well studied example. ${ }^{20}$ In particular, for planar molecules, the equilibrium inertial defect, $\Delta_{\mathrm{e}}$, is closer to zero when calculated from the semiexperimental constants. For instance, in the case of $\mathrm{HNO}_{3},{ }^{22} \Delta_{\mathrm{e}}=0.0002 \mathrm{u \AA} \AA^{2}$ with the semiexperimental rotational constants and $\Delta_{\mathrm{e}}=0.0069 \mathrm{u}^{2}$ when the available experimental $\alpha$ 's replace the ab initio ones. It might be tempting to think that, in the presence of interactions, the system of normal equations becomes ill-conditioned and, therefore, the derived parameters are not accurate. However, fixing the non-diagonal interaction parameters to the $a b$ initio values does not significantly improve the situation. Another possible explanation is that the levels may be affected by anharmonic resonances, even if they are far away as was shown by Saito in the particular case of $\mathrm{SO}_{2}{ }^{47}$ However, the provisional conclusion is that there is no obvious explanation.

Another interesting result of this study is that the large amplitude motion of the $\mathrm{OH}$ group does not hinder an accurate determination of the semiexperimental structure. In the particular case of $\mathrm{BF}_{2} \mathrm{OH}$, there are two problems: there is not enough experimental data because there is no isotopic substitution available for the fluorine atoms and the boron atom is extremely close to the center of mass; therefore, its substitution does not bring any useful information. Furthermore, $\mathrm{BF}_{2} \mathrm{OH}$ is an oblate top with the moment of inertia $I_{c}$ much larger than the other two moments of inertia, $I_{a}$ and $I_{b}$. Molecules of this shape experience a large rotation of the principal axis system upon certain isotopic substitutions. For such isotopologues it is difficult to obtain a good structural fit to the semiexperimental moments of inertia, $I_{a}$ and $I_{b}$. To achieve an accurate structure, the mixed estimation method is used. In this method, internal coordinates of good 
quality quantum chemical calculations (with appropriate uncertainties) are fitted simultaneously with the semiexperimental moments of inertia of all isotopologues.

A very accurate $a b$ initio structure can be obtained either by direct optimization at the convergence limit, $\operatorname{CCSD}(\mathrm{T}) \_\mathrm{AE} /$ cc-pwCVQZ, or by the less expensive additive method based on the $\operatorname{CCSD}(\mathrm{T}) \_\mathrm{AE} / \mathrm{cc}$-pwCVTZ structure improved by small corrections to the convergence limit calculated at the MP2 level. In any case, the core-core and core-valence correlation effects have to be taken into account in the accurate structure calculations because they are very large $(\approx 0.003 \AA$ for $\mathrm{BF}$ and $\mathrm{BO}$ bond lengths).

\section{Appendix: Hamiltonian}

The $v$-diagonal block is a standard Watson Hamiltonian in A-reduction and representation $\mathrm{I}^{\mathrm{r}}$. However, for $\mathrm{BF}_{2} \mathrm{OH}$, the $\nu_{4}$ mode $\left(\mathrm{OH}\right.$ in plane bending) and the $\nu_{9}$ mode $(\mathrm{OH}$-torsion relative to the $\mathrm{BF}_{2}$ moiety) are large amplitude motions. ${ }^{9}$ As a consequence, for each of the $\left\{4^{1}, 7^{1} 9^{1}, 6^{1} 7^{1}, 9^{2}, 6^{1} 9^{1}\right\}$ interacting states the v-diagonal blocks also include an $\mathbf{X Z}_{v}$, non-orthorhombic operator

$$
\mathbf{X Z}_{v}=h_{x z}^{v}\left\{\hat{J}_{x} \hat{J}_{z}\right\}+\cdots
$$

with

$$
\{\hat{A}, \hat{B}\}=\hat{A} \hat{B}+\hat{B} \hat{A}
$$

These $\mathbf{X Z}_{v}$ non-orthorhombic operators account for the rather strong Coriolis interactions linking the two $4^{1}$ bending or $\left(9^{2}\right.$ torsional) sub-states. In addition the tunnelling splittings due to the large amplitude $\mathrm{OH}$ bending (for the $v_{4}$ band) or $\mathrm{OH}$ torsion (for the $2 \nu_{9}$ band) had to be accounted for by specific bending or torsional operators in the $4^{1}$ and $9^{2}$ vibrational blocks. As in ref. 9 and 48, these operators written in the internal axis method (IAM)-like approach involve matrix elements of the $D(\chi, \theta, \varphi)$ Wigner operators, where $\chi, \theta$ and $\varphi$ are the Euler angles, with $\chi=\varphi+\pi$ for symmetry considerations

$$
\begin{aligned}
\left\langle J K^{\prime} \gamma^{\prime}|\hat{H}| J K^{\prime \prime} \gamma^{\prime \prime}\right\rangle= & \varepsilon(-1)^{K^{\prime}}\left(\cos \left(\left(K^{\prime}+K^{\prime \prime}\right) \varphi\right) d_{K^{\prime}, K^{\prime \prime}}^{(J)}(\theta)\right. \\
& \left.+\gamma^{\prime \prime} \cos \left(\left(K^{\prime}-K^{\prime \prime}\right) \varphi\right) d_{K^{\prime},-K^{\prime \prime}}^{(J)}(\theta)\right)
\end{aligned}
$$

The elements off-diagonal in $v$ include Coriolis operators

A-type Coriolis:

$$
v^{\prime, v} \hat{A}=v^{v^{\prime}, v} A_{z} \hat{J}_{z}+{ }^{v^{\prime}, v} A_{x y}\left\{\hat{J}_{x}, i \hat{J}_{y}\right\}+\ldots
$$

B-type Coriolis:

$$
\begin{aligned}
{ }^{v^{\prime}, v} \hat{B}= & { }^{v^{\prime}, v} B_{x} \hat{J}_{x}+{ }^{v^{\prime}, v} B_{y z}\left\{i \hat{J}_{y}, \hat{J}_{z}\right\}+{ }^{v^{\prime}, v} B_{x J} \hat{J}_{x} \hat{J}^{2} \\
& +{ }^{v^{\prime}, v} B_{x z z}\left\{\hat{J}_{z}^{2}, \hat{J}_{x}\right\}+{ }^{v^{\prime}, v} B_{x 3}\left(\hat{J}_{+}^{3}+\hat{J}_{-}^{3}\right)
\end{aligned}
$$

with

$$
\hat{J}_{ \pm}=\hat{J}_{x} \mp i \hat{J}_{y}
$$

C-type Coriolis:

$$
{ }^{v^{\prime}, v} \hat{C}={ }^{v^{\prime}, v} C_{y} i \hat{J}_{y}+{ }^{v^{\prime}, v} C_{x z}\left\{\hat{J}_{x}, \hat{J}_{z}\right\}
$$

as well as Fermi and anharmonic terms

$$
v^{\prime}, v \hat{A} n h={ }^{v^{\prime}, v} A n h_{0}+{ }^{v^{\prime}, v} A n h_{x y} \hat{J}_{x y}{ }^{2}+{ }^{v^{\prime}, v} A n h_{x y z z}\left\{\hat{J}_{z}{ }^{2}, \hat{J}_{x y}{ }^{2}\right\}
$$

with

$$
\hat{J}_{x y}{ }^{2}=\hat{J}_{x}^{2}-\hat{J}_{y}^{2}
$$

\section{Acknowledgements}

We thank Prof H. Bürger (Wuppertal) for his essential help at the beginning of this investigation. We also thank Dr J. Breidung (Mülheim) for providing us the details of the force field of ${ }^{11} \mathrm{BF}_{2} \mathrm{OD}$ and the reviewers for their careful reading of the manuscript. This work was supported by the Dr B. Mez-Starck Foundation (Germany).

\section{Notes and references}

1 R. F. Porter, D. R. Bidinosti and K. F. Watterson, J. Chem. Phys., 1962, 36, 2104-2108.

2 H. Takeo and R. F. Curl, J. Chem. Phys., 1972, 56, 4314-4317.

3 K. Vormann and H. Dreizler, Z. Naturforsch., 1989, 44a, 1191-1195.

4 J. Breidung, J. Demaison, J. F. D’Eu, L. Margulès, D. Collet, E. B. Mkadmi, A. Perrin and W. Thiel, J. Mol. Spectrosc., 2004, 228, 7-22.

5 L. H. Coudert, P. Garcia-Fernandez, H. Mäder, J. Demaison and J. E. Boggs, J. Phys. Chem. A, 2008, 112, 1536-1544.

6 M. E. Jacox, K. K. Irikura and W. E. Thompson, J. Chem. Phys., 2000, 113, 5705-5715.

7 D. Collet, A. Perrin, H. Bürger and J.-M. Flaud, J. Mol. Spectrosc., 2002, 212, 118-124.

8 A. Perrin, M. Cavajal-Zaera, Z. Dutkiewicz, J.-M. Flaud, D. Collet, H. Bürger, J. Demaison, F. Willaert, H. Mäder and N. W. Larsen, Mol. Phys., 2004, 102, 1641-1652.

9 A. Perrin, E. Bertseva, J.-M. Flaud, D. Collet, H. Bürger, T. Masiello and T. A. Blake, Mol. Phys., 2007, 105, 1833-1848.

10 A. Perrin, J. Demaison and H. Bürger, J. Quant. Spectrosc. Radiat. Transfer, 2012, 113, 1226-1232.

11 F. J. Melendez, C. Muñoz-Caro, A. Niño, J. Sandoval-Lira and A. Rangel-Huerta, Int. J. Quantum Chem., 2011, 111, 4389-4399.

12 J. Demaison, A. G. Császár, L. Margulès and H. D. Rudolph, J. Phys. Chem. A, 2011, 115, 14078-14091.

13 J. Demaison and H. D. Rudolph, J. Mol. Spectrosc., 2008, 248, 66-76.

14 J. Demaison, L. Margulès, I. Kleiner and A. G. Császár, J. Mol. Spectrosc., 2010, 259, 70-79.

15 J. Demaison, A. G. Császár, I. Kleiner and H. Møllendal, J. Phys. Chem. A, 2007, 111, 2574-2586.

16 J. Demaison, L. Margulès and H. D. Rudolph, J. Mol. Struct., 2010, 978, 229-233.

17 N. Vogt, J. Demaison, J. Vogt and H. D. Rudolph, J. Comput. Chem., 2014, 35, 2333-2342. 
18 J. Demaison, A. G. Császár and A. Dehayem-Kamadjeu, J. Phys. Chem. A, 2006, 110, 13609-13617.

19 V. Sironneau, J. Orphal, J. Demaison and P. Chelin, J. Phys. Chem. A, 2008, 112, 10697-10702.

20 J. Demaison, M. Herman and J. Liévin, J. Chem. Phys., 2007, 126, 164305.

21 W. D. Allen, E. Czinki and A. G. Császár, Chem. - Eur. J., 2004, 10, 4512-4517.

22 C. Gutle, J. Demaison and H. D. Rudolph, J. Mol. Spectrosc., 2009, 254, 99-107.

23 J. Demaison, J. E. Boggs and H. D. Rudolph, J. Mol. Struct., 2004, 695-696, 145-153.

24 J. Demaison, J. Mol. Spectrosc., 2006, 239, 201-207.

25 L. S. Rothman, I. E. Gordon, Y. Babikov, A. Barbe, D. C. Benner, P. F. Bernath, M. Birk, L. Bizzocchi, V. Boudon, L. R. Brown, A. Campargue, K. Chance, E. A. Cohen, L. Coudert, V. M. Devi, B. J. Drouin, A. Fayt, J. M. Flaud, R. R. Gamache, J. Harrison, J. M. Hartmann, C. Hill, J. T. Hodges, D. Jacquemart, A. Jolly, J. Lamouroux, R. J. LeRoy, G. Li, D. A. Long, C. J. Mackie, S. T. Massie, S. Mikhailenko, H. S. P. Müller, O. V. Naumenko, A. V. Nikitin, J. Orphal, V. Perevalov, A. Perrin, E. R. Polovtseva, C. Richard, M. A. H. Smith, E. Starikova, K. Sung, S. Tashkun, J. Tennyson, G. C. Toon, V. G. Tyuterev and G. Wagner, J. Quant. Spectrosc. Radiat. Transfer, 2013, 130, 4-50.

26 T. Masiello, A. Maki and T. A. Blake, J. Mol. Spectrosc., 2005, 234, 122-136.

27 J. K. G. Watson, in Vibrational spectra and structure, ed. J. R. Durig, Elsevier, Amsterdam, 1977, vol. 6, pp. 1-89.

28 G. D. Purvis III and R. J. Bartlett, J. Chem. Phys., 1982, 76, 1910-1918.

29 K. Raghavachari, G. W. Trucks, J. A. Pople and M. HeadGordon, Chem. Phys. Lett., 1989, 157, 479-483.

30 T. H. Dunning, Jr., J. Chem. Phys., 1989, 90, 1007-1023.

31 C. Møller and M. S. Plesset, Phys. Rev., 1934, 46, 618-622.

32 J. M. L. Martin and P. R. Taylor, Chem. Phys. Lett., 1994, 225, 473-479.
33 R. A. Kendall, T. H. Dunning, Jr. and R. J. Harrison, J. Chem. Phys., 1992, 96, 6796-6806.

34 K. A. Peterson and T. H. Dunning Jr., J. Chem. Phys., 2002, 117, 10548-10560.

35 N. Vogt, L. S. Khaikin, O. E. Grikina and A. N. Rykov, J. Mol. Struct., 2013, 1050, 114-121.

36 N. Vogt, J. Demaison, D. N. Ksenafontov and H. D. Rudolph, J. Mol. Struct., 2014, 1076, 483-489.

37 N. Vogt, I. I. Marochkin, A. N. Rykov and O. V. Dorofeeva, J. Phys. Chem. A, 2013, 117, 11374-11381.

38 N. Vogt, I. I. Marochkin and A. N. Rykov, J. Phys. Chem. A, 2015, 119, 152-159.

39 W. D. Allen and A. G. Császár, J. Chem. Phys., 1993, 98, 2983-3015.

40 W. Kohn and L. J. Sham, Phys. Rev. [Sect.] A, 1965, 140, 1133-1138.

41 T. Schwabe and S. Grimme, Phys. Chem. Chem. Phys., 2007, 9, 3397-3406.

42 L. S. Bartell, D. J. Romanesko and T. C. Wong, in Chemical Society Specialist Periodical Report N20: Molecular Structure by Diffraction Methods, ed. G. A. Sims and L. E. Sutton, The Chemical Society, London, 1975, vol. 3, pp. $72-79$.

43 J. Demaison, in Equilibrium Molecular Structures; ed. J. Demaison, J. E. Boggs and A. G. Császár, CRC Press, Boca Raton, 2011, pp. 29-52.

44 D. A. Belsley, Conditioning Diagnostics, Wiley, New York, 1991.

45 J. Demaison, M. Herman and J. Liévin, Int. Rev. Phys. Chem., 2007, 26, 391-420.

46 L. Margulès, J. Demaison and J. E. Boggs, THEOCHEM, 2000, 500, 245-258.

47 S. Saito, J. Mol. Spectrosc., 1969, 30, 1-16.

48 A. Perrin, J. Orphal, J.-M. Flaud, S. Klee, G. Mellau, H. Mäder, D. Walbrodt and M. Winnewisser, J. Mol. Spectrosc., 2004, 228, 375-391. 